\title{
IS STRIAE GRAVIDARUM RELATED TO CESAREAN SCAR AND PERITONEAL ADHESIONS?
}

\footnotetext{
1. MBBS, FCPS

Senior Registrar Obs \& Gyne

Bahawal Victoria Hospital

Bahawalpur.

2. MBBS, FCPS

Assistant Professor Obs \& Gyne

Bakhtawar Amin Medical College, Multan.

3. MBBS, FCPS, MRCOG (Uk)

Senior Registrar Obs \& Gyne Bahawal Victoria Hospital Bahawalpur.
}

Correspondence Address:

Dr. Humaira Imran

House No. 593/11 Street No.1

Shadaab Colony,

Near MDA Chowk, Multan.

drfarrukhzaidi@hotmail.com

Article received on:

21/05/2019

Accepted for publication:

24/10/2019

\begin{abstract}
Sarwat Faridi', Humaira Imran², Bushra Mukhtar ${ }^{3}$
ABSTRACT... Objectives: Determination of the relationship among the peritoneal adhesions, cesarean scar and striae gravidarum. Study Design: Cross sectional Study. Settings: Gynecology and Obstetrics Department of Bahawal Victoria Hospital, Bahawalpur. Period: June 2018 to May 2018. Material \& Methods: A total of 150 cases of cesarean section which presented at gynecology and obstetrics department of Bahawal Victoria Hospital, Bahawalpur were involved in this study. Davey scoring system was applied in order to determine the severity of striae gravidarum. Intraperitoneal adhesions were classified into five subcategories on the basis of Modified Blauer classification. Grouping was done on the random basis. Three groups were made. Group 1 consisted of the women with no striae gravidarum, group 2 had women with number of striae gravidarum from mild to moderate and group 3 had women of severe number of striae gravidarum. Comparison between different groups was done using the MannWhitney and student $T$ test. Mean and standard deviation were calculated for quantitative variables while qualitative variables were assessed by their frequency and percentage. Statistically significant $P$ value was 0.05 or less. Results: Intraperitoneal adhesions of grade $2-4$, pigmentations and keliods were frequent in group 2 and 3 but the difference between these groups was not statistically significant ( $p$-value $0.517,0.427$ and 0.372 , respectively). There was no difference present among the group regarding the appearance of scar as well $(p=0.541)$. As far as the length and width of the scar was concerned, the length was relatively more in patients of group 3 while width was relatively more in patients of group 1 but there were no statistically significant differences (Table-II) $(p=0.289$ and $p=0.248$ respectively). Conclusion: It can be concluded that there is no association between intraperitoneal adhesions and striae gravidarum but correlation between scar characteristics and striae gravidarum are evident.
\end{abstract}

Key words: $\quad$ Cesarean Section, Intraperitoneal Adhesions, Keliods, Pigmentations, Scars, Striae Gravidarum.

Article Citation: Faridi S, Imran H, Mukhtar B. Is striae gravidarum related to cesarean scar and peritoneal adhesions? Professional Med J 2020; 27(8):1550-1554. DOI: 10.29309/TPMJ/2020.27.08.3745

\section{INTRODUCTION}

Other name of striae gravidarum is striae distensae. These striae occur in various extents during the pregnancy and are very commonly observed during the gestation. ${ }^{1}$ Probable risk factors of striae gravidarum involve, age, weight, increase in BMI during pregnancy, BMI of the new born and ethnicity of the patients as well. ${ }^{2}$ Despite the recognition of all these risk factors no specific etiology has been defined as a cause of this condition during the pregnancy. ${ }^{3}$ Cleavage of collagen fibers as result of fast stretching of skin may be the probable case of development of striae during pregnancy. Type of collagen fibers and its total amount determines the elasticity and striae development as poor elasticity of the skin can result in easy cleavage of the collagen fibers and thus formation of striae gravidarum. Other probable cause can be reduced amount of elastin and fibrin in dermis and hormonal effects which might result in structural changes in connective tissue may also result in formation of striae gravidarum. ${ }^{4,5}$ As it has been evident from multiple previous studies that cesarean section which is performed very commonly all over the world carries the risk of potential adverse complications like intraperitoneal adhesions resulting in chronic pelvic pain, infertility and injury to bladder or bowel. 
Determination of the presence of intraperitoneal adhesions is very difficult. ${ }^{6}$ Moreover it is also very difficult to assess if the complications are going to be present in women who had major abdominal surgeries. ${ }^{7}$ This emphasizes on the need that preoperative measures must be taken in women who are at risk of developing the adhesions and thus such women should be referred to centers with tertiary care in order to avoid and deal with possible complications. No way or technique is present at the moment which can be used to diagnose the development of adhesions in patients prior to the repeat abdominal surgery like c-section. Formation of both intraperitoneal adhesions and striae gravidarum involve the protective role of elastin fibers and thus share almost similar pathway of tissue healing. ${ }^{8}$ This study aims at finding the relation between striae gravidarum and abdominal cars with intraperitoneal adhesions. This could help in determining the predictive value of striae gravidarum and abdominal scars in order to evaluate the presence or absence of abdominal adhesions.

\section{MATERIAL \& METHODS}

This study is cross sectional and was performed at gynecology and obstetrics department of Bahawal Victoria Hospital, Bahawalpur June 2018 to May 2018. Total of 150 cases of cesarean section which presented at gynecology and obstetrics department of gynecology and obstetrics department of Bahawal Victoria Hospital, Bahawalpur were involved in this study. Informed consent was obtained from the participants prior to the enrolment in the study. Ethical approval was obtained from hospital ethics committee.

Non probability consecutive sampling technique was used to collect the sample. Reference for this study was obtained from a previous study performed by Esra Yasar Celik et al. ${ }^{9}$ Patients presenting for cesarean section, with the history of at least one prior cesarean section were included in this study. Patients with previous vaginal delivery, suffering from endometriosis, pelvic inflammatory disease, abdominal or pelvic surgery other than cesarean section, multiple pregnancies, steroid use, infectious complications after last cesarean section including abscesses, wound infection and endometritis etc were excluded from this study. At the time of admission following parameters were measured and recorded in the form of a performed performa; age, parity, gravidity, gestational age of delivery, past and current, change in BMI during gestation. Moreover, striae scores, evidence of striae on different body parts and properties of incisional scar were noted. Davey scoring system was applied in order to determine the severity of striae gravidarum. Davey scoring system divides abdomen into quadrants, at each quadrant scoring is done as; 0 for no striae, 1 for moderate, or 2 for multiple striae. Sum of scores was sorted as $0-8$. Three severity of striae categories were defined as, $0=$ absent, $1-2=$ mild, $3-8=$ severe.

All the procedures were performed the researcher himself. Color of scar was observed and recorded based on the pigmentation of scar and plane of scar was termed as depressed, elevated or flat. Moreover presence of keloids was aslo noted. Obstetric history involved data regarding the indication, time and gestational age at last cesarean section, history of GDM (gestational diabetes mellitus), fetal macrosomy, polyhydromnios, BMI at the time of the delivery, weight gain during pregnancy, smoking, medication history, and any other chronic illness. Intraperitoneal adhesions were classified into five subcategories on the basis of Modified Blauer classification.

Five grades of intraperitoneal adhesion are, 0 indicated no adhesions, 1-2 indicated easily separable localized adhesions, 3 indicated extensive adhesions and 4 indicated adhesions present between bladder or uterus and the intestines. Grouping was done on the random basis. Three groups were made. Group 1 consisted of the women with no striae gravidarum, group 2 had women with number of striae gravidarum from mild to moderate and group 3 had women of severe number of striae gravidarum. Comparison between was made on the basis of characteristics of scars and intraperitoneal adhesions grades. Data thus collected was subjected to statistical analysis with help of computer software SPSS 
version 23. Comparison between different groups was done using the Mann-Whitney and student T test. Mean and standard deviation were calculated for quantitative variables while qualitative variables were assessed by their frequency and percentage. Statistically significant $P$ value was 0.05 or less.

\section{RESULTS}

Three groups were compared, group-1 with zero, Group 2 with mild and Group 3 with severe SG and no considerable difference in age, gravida, abortions, level of education, gap between two cesarean sections, birth weight of the baby born in previous cesarean section and birth weight of the baby born in current cesarean section $(p>0.05)$. SG in previous pregnancy and history of SG in family were considerably more in Group 3 ( $p$-value $<0.001$ and 0.005 , respectively). Striae on buttocks and breast were significantly more in Group-1 while striae on legs were significantly more in Group-3 (p-value 0.004, 0.024 and 0.008, respectively). $\mathrm{BMI}$ in previous $\mathrm{C} / \mathrm{S}, \mathrm{BMI}$ in present $\mathrm{C} / \mathrm{S}, \mathrm{GW}$ in previous $\mathrm{C} / \mathrm{S}$ and $\mathrm{GW}$ in present $\mathrm{C} / \mathrm{S}$ were highest in Group-3 and lowest in Group-1 and was statistically significant different ( $p$-value $0.017,0.040,0.002$ and $<0.001$, respectively). Table-I

Gr Intraperitoneal adhesions of grade 2-4, pigmentations and keliods were frequent in group 2 and 3 but the difference between these groups was not statistically significant ( $p$-value $0.517,0.427$ and 0.372 , respectively). There was no difference present among the group regarding the appearance of scar as well $(p=0.541)$. As far as the length and width of the scar was concerned, the length was relatively more in patients of group 3 while width was relatively more in patients of group 1 but there were no statistically significant differences (Table-II) $(p=0.289$ and $p=0.248$ respectively).

\begin{tabular}{|c|c|c|c|c|}
\hline Variable & $\begin{array}{c}\text { Group } 1 \\
n=47 \text { Zero }\end{array}$ & $\begin{array}{c}\text { Group } 2 \\
n=59 \text { Mild }\end{array}$ & $\begin{array}{c}\text { Group } 3 \\
\mathrm{n}=44 \text { Severe }\end{array}$ & P-Value \\
\hline Age (yrs) & $29.13 \pm 4.35$ & $28.49 \pm 4.89$ & $27.84 \pm 5.87$ & 0.479 \\
\hline Gravidity $(2 / 3 / 4 />4)$ & $13 / 19 / 15 / 0$ & $13 / 24 / 19 / 3$ & $12 / 12 / 15 / 5$ & 0.279 \\
\hline Abortions $(0 / 1 / 2 />2)$ & $24 / 15 / 8 / 0$ & $23 / 22 / 13 / 1$ & $19 / 12 / 10 / 3$ & 0.378 \\
\hline Education (primary/intermediate/college) & $14 / 16 / 17$ & $15 / 23 / 21$ & $12 / 21 / 11$ & 0.664 \\
\hline Income (low/middle/high) & $11 / 25 / 11$ & $10 / 32 / 17$ & $12 / 23 / 9$ & 0.725 \\
\hline$S G$ in first pregnancy $(+/-)$ & $6 / 41$ & $12 / 47$ & $36 / 8$ & $<0.001$ \\
\hline Family history of SG (+/-) & $24 / 23$ & $30 / 29$ & $35 / 9$ & 0.005 \\
\hline Striae on Buttocks (+/-) & $37 / 10$ & $29 / 30$ & $31 / 13$ & 0.004 \\
\hline Striae on legs $(+/-)$ & $26 / 21$ & $28 / 31$ & $34 / 10$ & 0.008 \\
\hline Striae on breast $(+/-)$ & $36 / 11$ & $30 / 29$ & $26 / 18$ & 0.024 \\
\hline interval blw 2 C-sections, (yrs) & $4.55 \pm 1.21$ & $4.31 \pm 1.25$ & $4.25 \pm 1.39$ & 0.476 \\
\hline Birth weight of $1^{\text {st }}$ baby, grams & $2820.62 \pm 442.87$ & $2832.34 \pm 550.61$ & $2899.18 \pm 464.07$ & 0.714 \\
\hline Birth weight of $2^{\text {nd }}$ baby, grams & $2721.64 \pm 485.88$ & $2765.53 \pm 486.14$ & $2889.30 \pm 471.79$ & 0.231 \\
\hline $\mathrm{BMI}$ at previous $\mathrm{C} / \mathrm{S}$ & $26(25-29)$ & $28(26-29)$ & $29(27-32)$ & 0.017 \\
\hline $\mathrm{BMI}$ at present $\mathrm{C} / \mathrm{S}$ & $27(25-29)$ & $28(26-29)$ & $29(28-31.75)$ & 0.040 \\
\hline GA at first $\mathrm{C} / \mathrm{S}$ & $38(37-38)$ & $39(38-39)$ & $40(40-41)$ & 0.002 \\
\hline GA at present $\mathrm{C} / \mathrm{S}$ & 37 (37-39) & $39(38-40)$ & $39(38-41)$ & $<0.001$ \\
\hline
\end{tabular}

\begin{tabular}{|l|c|c|c|c|}
\hline \multicolumn{1}{|c|}{ Variable } & $\begin{array}{c}\text { Group 1 } \\
\mathbf{n = 4 7 \text { Zero }}\end{array}$ & $\begin{array}{c}\text { Group 2 } \\
\mathbf{n = 5 9} \text { Mild }\end{array}$ & $\begin{array}{c}\text { Group 3 } \\
\mathbf{n = 4 4} \text { Severe }\end{array}$ & P-Value \\
\hline IPAs (0 to1/2 to4) & $38 / 9$ & $42 / 17$ & $33 / 11$ & 0.517 \\
\hline Keloids (+/-) & $9 / 38$ & $12 / 47$ & $13 / 31$ & 0.427 \\
\hline Pigmentation (+/-) & $11 / 36$ & $16 / 43$ & $16 / 28$ & 0.372 \\
\hline Scar appearance (flat/depressed/elevated) & $32 / 6 / 9$ & $39 / 7 / 13$ & $30 / 9 / 5$ & 0.541 \\
\hline Scar length, cm & $14.89 \pm 1.99$ & $14.97 \pm 1.41$ & $15.48 \pm 2.41$ & 0.289 \\
\hline Scar width, $\mathrm{cm}$ & $2.69 \pm 0.69$ & $2.54 \pm 0.52$ & $2.51 \pm 0.37$ & 0.248 \\
\end{tabular}




\section{DISCUSSION}

Over the years rate of primary cesarean section has increased while the rate of vaginal birth after the cesarean section has decreased enormously. ${ }^{10}$ A previous study has reported the overall average rate of cesarean section all over the world to be 15 percent approximately with many discrepancies among different countries and even within different countries. ${ }^{11}$ Intra abdominal adhesions may result in serious complications including chronic pelvic pain, bowel injury, infertility, bladder injury, bowel obstruction and increased duration of the surgery and its cost. ${ }^{12}$ Relaxin hormone has been reported to decrease the collaged production and increasing the collagen breakdown and thus is helpful in inhibiting the excessive collagen buildup. ${ }^{13}$ In a study it was found that in pregnant women with striae gravidarum amount of relaxin was lower as compared to the women with no striate gravidarum. ${ }^{14}$

Another study by Brecht et $\mathrm{al}^{15}$ showed that relaxin is involved in the inhibition of primary steps of vascular formation. Relaxin is a potent vasodilator and anti fibrotic agent. Thus it can be concluded from these observations that women with greater number of striae gravidarum are more likely to have greater number of keloids, non flat scar and intraperitoneal adhesions. In present study however no association between intraperitoneal adhesions and striae gravidarum could be found. In a previous study sensitivity and specificity of striae gravidarum in prediction of intraperitoneal adhesions has been reported be 95.2 percent and $29.4 \%$ respectively. ${ }^{16}$ More severe striae gravidarum were associated with poor sensitivity but higher specificity for the prediction of intraperitoneal adhesions.

In a previous study the results showed that as the scores for abdominal striae gravidarum increased, the score for abdominal adhesions decreased with it. This makes the scoring system of striae gravidarum as very useful, easy to apply, adjunctive, inexpensive, observational and feasible method to predict and provide clues to the presence of intraperitoneal adhesions in pregnant women scheduled for another cesarean section. ${ }^{8}$ Another similar study also deduced that presence and quantification of abdominal striae gravidarum in pregnant women undergoing cesarean section is a reliable tool which can provide the surgeon with necessary information regarding the status of abdominal adhesions. ${ }^{17}$ Similarly abdominal scars also have a relation with the possible presence of abdominal adhesions as a study revealed that intra abdominal adhesions were related to depressed abdominal scars but these adhesions had no association with the level of pigmentation of the scar. ${ }^{18}$

\section{CONCLUSION}

It can be concluded that there is no association between intraperitoneal adhesions and striae gravidarum but correlation between scar characteristics and striae gravidarum are evident.

\section{CONFLICT OF INTEREST}

There was no conflict of interest.

\section{Funding Source}

No external funding source was used.

Copyright $@ 24$ Oct, 2019.

\section{REFERENCES}

1. Picard D, Sellier S, Houivet E, Marpeau L, Fournet $\mathrm{P}$, Thobois B, Bénichou J, Joly P. Incidence and risk factors for striae gravidarum. J Am Acad Dermatol. 2015 Oct $1 ; 73(4): 699-700$.

2. Tang-Lin L, Liew HM, Koh MJ, Allen JC, Tan TC. Prevalence of striae gravidarum in a multi-ethnic Asian population and the associated risk factors. Australas J Dermatol. 2017; 58(3):e154-e155.

3. Farahnik B, Park K, Kroumpouzos G, Murase J. Striae gravidarum: Risk factors, prevention, and management. Int J Womens Dermatol. 2016; 3(2):7785.

4. Ersoy E, Ersoy AO, Yasar Celik E, Tokmak A, Ozler S, Tasci $Y$. Is it possible to prevent striae gravidarum? J Chin Med Assoc. 2016; 79(5):272-275.

5. Wang F, Calderone K, Smith NR, Do TT, Helfrich YR, Johnson TR, Kang S, Voorhees JJ, Fisher GJ. Marked disruption and aberrant regulation of elastic fibres in early striae gravidarum. Brit J Dermatol. 2015; 173(6):1420-30.

6. Buțureanu SA, Buțureanu TA. Pathophysiology of adhesions. Chirurgia (Bucharest, Romania: 1990). 2014; 109(3):293-8. 
7. Catena F, Di Saverio S, Coccolini F, Ansaloni L, De Simone B, Sartelli M, Van Goor H. Adhesive small bowel adhesions obstruction: Evolutions in diagnosis, management and prevention. World j gastroint surg. 2016; 8(3):222.

8. Dogan A, Ertas IE, Uyar I, Karaca I, Bozgeyik B, Töz E, Ozeren M. Preoperative association of abdominal striae gravidarum with intraabdominal adhesions in pregnant women with a history of previous cesarean section: A cross-sectional study. Geburtshilfe und Frauenheilkunde. 2016; 76(3):268.

9. Celik EY, Ersoy AO, Ersoy E, Yoruk O, Tokmak A, Tasci $Y$. Is striae gravidarum related to cesarean scar and peritoneal adhesions?. Pakistan Journal of Medical Sciences. 2018 May;34(3):568.

10. Hamilton BE, Martin JA, Sutton PD. Births: Preliminary data for 2003. Natl Vital Stat Rep. 2004; 53(9):1-17.

11. Betran AP, Merialdi M, Lauer JA, Bing- Shun W, Thomas J, Van Look $P$, etal. Rates of caesarean section: Analysis of global, regional and national estimates. Paediatr Perinat Epidemiol. 2007; $21(2): 98-113$.

12. Awonuga AO, Fletcher NM, Saed GM, Diamond MP. Postoperative adhesion development following cesarean and open intra-abdominal gynecological operations: A review. Reprod Sci. 2011; 18(12):116685.
13. Dehghan F, Haerian BS, Muniandy S, Yusof A, Dragoo JL, Salleh N. The effect of relaxin on the musculoskeletal system. Scand J Med Sci Sports. 2014; 24(4):e220-e229.

14. Lurie S, Matas Z, Fux A, Golan A, Sadan O. Association of serum relaxin with striae gravidarum in pregnant women. Arch Gynecol Obstet. 2011; 283(2):219-22.

15. Brecht A, Bartsch C, Baumann G, Stangl K, Dschietzig T. Relaxin inhibits early steps in vascular inflammation. Regul Pept. 2011; 166(1-3):76-82.

16. Cakir Gungor AN, Oguz S, Hacivelioglu S, Isik S, Uysal A, Gencer $M$, etal. Predictive value of striae gravidarum severity for intraperitoneal adhesions or uterine scar healing in patients with previous caesarean delivery. J Matern Fetal Neonatal Med. 2014; 27(13):1312-1315.

17. Kahyaoglu I, Kayikcioglu F, Kinay T, Mollamahmutoglu L. Abdominal scar characteristics: Do they predict intra $\square$ abdominal adhesions with repeat cesarean deliveries?. J Obstet Gynaecol Res. 2014; 40(6):16438.

18. Dogan NU, Haktankacmaz SA, Dogan S, Ozkan O, Celik H, Eryilmaz OG, Doganay M, Gulerman C. A reliable way to predict intraabdominal adhesions at repeat cesarean delivery: Scar characteristics. Acta obstetricia et gynecologica Scandinavica. 2011; 90(5):531-4.

\begin{tabular}{|c|l|l|l|}
\hline \multicolumn{3}{|c|}{ AUTHORSHIP AND CONTRIBUTION DECLARATION } \\
\hline Sr. \# & Author(s) Full Name & Contribution to the paper & Author(s) Signature \\
\hline 1 & Sarwat Faridi & Data analysis. & Sfaridi \\
\hline 2 & Humaira Imran & Concept \& Design of Study. & Hiwaira \\
3 & Bushra Mukhtar & Drafting. & Bushou \\
\hline
\end{tabular}

